\title{
Intoxicação por metotrexato: relato de caso
}

Ana Mafalda Ventura, ${ }^{1}$ Maria Paula Fernandes, ${ }^{2}$ Fátima Franco, ${ }^{2}$ Ana Luísa Gomes ${ }^{3}$

\begin{abstract}
RESUMO
Introdução: Os medicamentos de alerta máximo têm um potencial de causar dano ao doente em caso de utilização incorreta, devido à gravidade dos seus efeitos adversos. O metotrexato (MTX) é um antimetabolito frequentemente utilizado no tratamento de doenças reumatológicas e um exemplo de medicamento de alerta máximo.

Descrição de caso: Apresenta-se o caso de um doente de 64 anos que recorreu ao médico de família por quadro de disfagia, sensação de globus faríngeo, lesões cutâneas eritematosas pruriginosas e halitose. À observação apresentava extensa mucosite oral com edema da orofaringe. Após revisão terapêutica constatou-se que, por erro de interpretação, estaria a fazer diariamente 17,5mg de MTX com pausa semanal. Foi então referenciado ao serviço de urgência para observação por ORL e dermatologia e investigação adicional do quadro, nomeadamente de eventual toxicidade medular.

Comentário: A forma mais comum de toxicidade por MTX é a sobredosagem acidental pelo doente, geralmente com efeitos secundários graves, podendo mesmo ser fatal. Este caso permite refletir sobre alguns aspetos importantes na segurança do medicamento com este tipo de fármacos.
\end{abstract}

Palavras-chave: Intoxicação; Metotrexato; Medicamentos de alerta máximo; Segurança na medicação.

\section{INTRODUÇÃO}

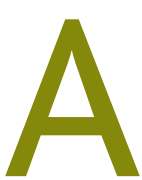

medicina geral e familiar caracteriza-se pelo cuidar holístico centrado na pessoa. $\mathrm{O}$ acompanhamento do doente é feito ao longo do seu ciclo de vida, respeitando a sua autonomia e proporcionando cuidados de forma abrangente, contínua e coordenada, frequentemente em conjunto com outras especialidades. ${ }^{1}$

A comunicação com o doente e entre os diferentes prestadores de cuidados é especialmente importante no contexto da decisão terapêutica e minimização de erros de medicação, em particular na gestão de medicamentos considerados de alerta máximo.

Os medicamentos de alerta máximo são aqueles que possuem um risco aumentado de provocar dano significativo ao doente em consequência de falhas no seu processo de utilização. Embora os erros que possam ocorrer com estes medicamentos não sejam os mais frequentes, as suas consequências tendem a ser mais graves, podendo ocasionar lesões permanentes ou in-

1. Médica Assistente de Medicina Geral e Familiar. USF Cruzeiro, ACeS Loures-Odivelas.

2. USF Ramada, ACeS Loures-Odivelas.

3. USF Novo Mirante, ACeS Loures-Odivelas. clusivamente a morte, aumentando os custos associados aos cuidados de saúde prestados ao doente. ${ }^{2}$

O metotrexato (MTX) é provavelmente o mais bem estudado fármaco modificador da ação da doença utilizado em patologias reumáticas. É um antimetabolito e antagonista do ácido fólico, utilizado no tratamento de várias doenças crónicas, particularmente nas reumatológicas (disease-modifying anti-rheumatic drug) $\cdot^{3-6}$ Os seus efeitos são diversos, atuando numa multiplicidade de vias metabólicas e, consequentemente, com uma potencial multiplicidade de efeitos adversos. ${ }^{4}$ É, por isso, considerado um medicamento de alerta máximo.

\section{DESCRIÇÃO DO CASO}

Doente de 64 anos, género masculino, casado, pertencente a uma família nuclear, na fase VII do Ciclo de Duvall, classe III de Graffar, motorista reformado de pesados de passageiros, com o sexto ano de escolaridade. Como antecedentes pessoais apresentava hipertensão arterial, diabetes mellitus não insulino-tratada, dislipidemia, hiperuricemia, psoríase e artrite psoriática, sendo acompanhado em consulta de medicina geral e familiar, reumatologia e dermatologia. Encontrava-se medicado com olmesartan medoxomilo $20 \mathrm{mg}$ id, 
saxagliptina $5 \mathrm{mg}$ id, sinvastatina $40 \mathrm{mg}$ id, alopurinol $100 \mathrm{mg}$ id, betametasona + calcipotriol, $05 \mathrm{mg} / \mathrm{g}+$ 0,05mg/g pomada id, ácido fólico $5 \mathrm{mg}$ id e MTX (segundo esquema).

No contexto do diagnóstico de artrite psoriática em 2013, o doente iniciou terapêutica com MTX semanal na dose de $11,5 \mathrm{mg}$, com controlo sintomático. O cumprimento terapêutico foi adequado relativamente à dose e frequência, sem reações adversas reportadas. Por agravamento das queixas articulares e impotência funcional dos punhos e mãos foi ajustada a dose de MTX semanal para 17,5mg, tendo o reumatologista entregue a respetiva guia de tratamento em papel e a receita do fármaco.

Posteriormente, o utente recorre à consulta de doença aguda na USF por dificuldade em deglutir e colocar a prótese dentária, halitose e lesões cutâneas generalizadas e pruriginosas dispersas pelo corpo, referindo agravamento progressivo com mais de uma semana de evolução.

Ao exame objetivo observou-se edema da face, halitose intensa, orofaringe edemaciada com extensas placas brancas destacáveis, úlceras orais e sensação de globus faríngeo; manchas eritematosas, descamativas, pruriginosas com predomínio no tronco e abdómen. Encontrava-se hemodinamicamente estável, eupneico em ar ambiente e apirético.

Após revisão terapêutica constatou-se que, devido a um erro de interpretação das instruções fornecidas, o doente percebeu que a toma da nova dosagem de MTX seria diária, com um dia de pausa semanal, no qual fazia suplementação com ácido fólico.

Encontrava-se desta forma a fazer uma dosagem semanal de 105mg de MTX, quando a dose habitualmente utilizada na prática clínica é de 15 a $20 \mathrm{mg}$ por semana. ${ }^{3}$

Foi identificada uma sobredosagem de MTX compatível com a sintomatologia clínica apresentada e o doente foi referenciado ao serviço de urgência com a hipótese de diagnóstico de mucosite associada a intoxicação por MTX.

Prevendo-se necessidade de internamento, foi acordado com o doente a sua reavaliação em consulta na USF após a alta hospitalar, promovendo e sensibilizando o utente para o processo de reconciliação terapêutica.

O doente ficou internado por mucosite secundária a MTX com sobreinfeção fúngica (candidíase oral por

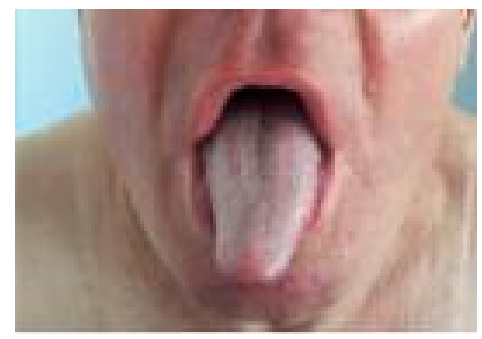

Figura 1. Mucosite oral em resolução (reavaliação após internamento hospitalar).

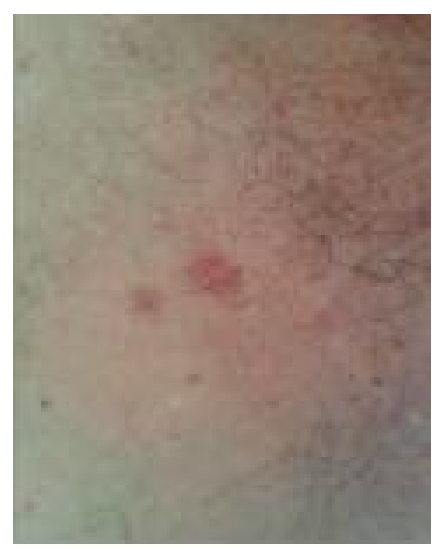

Figura 2. Rash (reavaliação após internamento hospitalar).

provável imunossupressão secundária). Laboratorialmente (à admissão) destacava-se leucócitos de $4.000 / \mathrm{mm}^{3}$, trombocitopenia $\left(97.000 / \mathrm{mm}^{3}\right)$, ALT 73 UI/L e PCR 5,37mg/dL. A terapêutica com MTX foi suspensa e cumpriu terapêutica endovenosa com antifúngico e corticoterapia tópica. Teve alta após quatro dias de internamento, clinicamente melhorado e com indicação para completar 14 dias de antifúngico oral.

Após a resolução do quadro, o doente retomou a prescrição inicial de MTX, de acordo com indicação reumatologia.

\section{COMENTÁRIO}

A acessibilidade à consulta de medicina geral e familiar em situação de doença aguda foi fundamental para a identificação e orientação célere da etiologia do quadro clínico. A intoxicação medicamentosa deve ser uma causa a considerar nos doentes tratados com medicamentos de alerta máximo.

A intoxicação por MTX pode ser aguda (em doentes sob MTX por um período inferior a sete dias) ou crónica 
(se superior a sete dias). ${ }^{5} \mathrm{~A}$ forma mais comum de toxicidade por MTX é a sobredosagem acidental pelo doente. ${ }^{5-6}$ Os efeitos adversos do MTX são normalmente de intensidade ligeira a moderada e as manifestações clínicas mais frequentes são as gastrointestinais (como náuseas, vómitos, diarreia), mucosite, úlceras orais, neurológicas (cefaleias, tonturas, vertigens), rash, alopecia, reações anafiláticas, candidíase, exantemas, entre outras. Os efeitos major centram-se na toxicidade pulmonar, da medula óssea ou na fibrose e cirrose he-

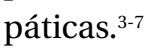

A pancitopenia é dos efeitos mais preocupantes pois, para além de imprevisível e com evolução rápida, pode ser fatal, dado o grave estado de imunossupressão que acarreta. ${ }^{4}$

A suplementação com ácido fólico veio melhorar a sintomatologia secundária responsável por muitas das suspensões da terapêutica com MTX, nomeadamente gastrointestinal, hepática e a alopecia. ${ }^{4}$

À semelhança dos quadros descritos na literatura, ${ }^{5-6}$ este doente desenvolveu um quadro de intoxicação crónica grave, apresentando mucosite com sobreinfecção secundária, rash cutâneo e toxicidade medular e hepática, que reverteram após a suspensão temporária do fármaco e tratamento direcionado.

Este caso permite refletir sobre alguns aspetos importantes da segurança na medicação e minimização de incidentes com a mesma. A reconciliação terapêutica é um processo multidisciplinar e centrado no doente, com foco nos pontos vulneráveis de transição de cuidados e que contribui de forma significativa para a redução de incidentes relacionados com a medicação. As instituições prestadoras de cuidados de saúde devem fornecer assistência aos doentes com o objetivo de recolha de informação o mais exata possível. ${ }^{8}$

Em qualquer medicamento, sobretudo em medicamentos de alerta máximo, pelo seu potencial acrescido de dano, é fundamental que o doente conheça os potenciais efeitos adversos e que lhe sejam fornecidas instruções claras, por escrito, garantindo que o esquema terapêutico foi corretamente compreendido.

A educação dos doentes deve ser um foco prioritário neste processo, promovendo uma responsabilização e envolvimento no seu processo de cuidados. ${ }^{7-8}$

\section{REFERÊNCIAS BIBLIOGRÁFICAS}

1. Allen J, Gay B, Crebolder H, Heyman J, Svab I, Ram P, et al. A definição Europeia de Medicina Geral e Familiar (clínica geral/medicina familiar) [The European definition of Family Medicine (general practice/family medicine)]. Rev Port Med Geral Fam. 2005;21(5):511-6. Portuguese

2. Direção-Geral da Saúde. Medicamentos de alerta máximo: norma n. ${ }^{\circ}$ 014/2015, de 06/08/2015. Lisboa: DGS; 2015.

3. Wilsdon TD, Whittle SL, Thynne TR, Mangoni AA. Methotrexate for psoriatic arthritis. Cochrane Database Syst Rev. 2019;(7):CD012722.

4. Neves C, Jorge R, Barcelos A. A teia de toxicidade do metotrexato. Acta Reumatol Port. 2009;34(1):11-34.

5. Ahmadzadeh A, Zamani N, Hassanian-Moghaddam H, Hadeiy SK, Parhizgar P. Acute versus chronic methotrexate poisoning; a cross-sectional study. BMC Pharmacol Toxicol. 2019;20(1):39.

6. Bidaki R, Kian M, Owliaey H, Zarch MB, Feysal M. Accidental chronic poisoning with methotrexate: report of two cases. Emerg (Tehran). 2017;5(1):e67.

7. Jones KW, Patel SR. A family physician's guide to monitoring methotrexate. Am Fam Physician. 2000;62(7):1607-14.

8. Direção-Geral da Saúde. Reconciliação da medicação: norma n. ${ }^{\circ}$ 018/2016, de 30/12/2016. Lisboa: DGS; 2016.

\section{CONFLITO DE INTERESSES}

Os autores declaram não ter quaisquer conflitos de interesse.

\section{ENDEREÇO PARA CORRESPONDÊNCIA}

Ana Mafalda Ventura

E-mail: ana.mafalda.pv@hotmail.com

https://orcid.org/0000-0002-0932-8577

Recebido em 03-09-2019

Aceite para publicação em 02-08-2020 


\section{ABSTRACT}

\section{METHOTREXATE INTOXICATION: A CASE REPORT}

Introduction: High-alert medications have an increased risk of causing significant patient harm when used incorrectly. Methotrexate (MTX) is an antimetabolite used in the treatment of rheumatologic diseases and an example of a high-alert medication.

Case report: We present the case of a 64 -year-old male who took daily $17,5 \mathrm{mg}$ of oral MTX despite using this medication for several years. The patient was evaluated for dysphagia, pruritic skin rash, and halitosis. The physical examination revealed extensive oral mucositis and oropharyngeal edema. After therapeutic review, it was realized that the patient was taking the prescribed dose daily instead of weekly. He was then referred to the emergency room to evaluate medullary involvement.

Comment: Patient accidental intoxication is the most common cause of MTX toxicity, frequently with severe side effects, which can be fatal. This case report allows reflecting on some important aspects of medication safety with this type of drug.

Keywords: Intoxication; Methotrexate; High-alert medication; Medication safety. 